\title{
In reply: Potential mechanism for bilateral sensory effects after a unilateral erector spinae plane block
}

\author{
Basak Altiparmak, MD 두 · Melike Korkmaz Toker, MD • Ali İhsan Uysal, MD
}

Received: 14 January 2020/Revised: 14 January 2020/ Accepted: 14 January 2020/Published online: 24 January 2020

(c) Canadian Anesthesiologists' Society 2020

\section{To the Editor,}

We thank Elkoundi et al. ${ }^{1}$ for their response to our recent letter. ${ }^{2}$ We speculated on two possible reasons for bilateral sensory block following a unilateral erector spinae plane (ESP) block. The first one was the facilitative effect of pneumoperitoneum, and the second one was the gravitational impact of positional changes on the spreading of local anesthetic (LA) solution. The authors opposed these hypothetical mechanisms on the basis of the study by Desmet et $a .^{3}$ In that study, Desmet et al. reported that the posterior spread of LA was not possible during a different interfascial plane technique, the transversus abdominis plane (TAP) block, where the observed LA extension was more craniocaudal. Nevertheless, despite being in an interfascial plane, the injection site of the ESP block is completely different from that of a TAP block. The LA solution is injected anatomically closer to the foramina of the targeted vertebra. Moreover, the possibility of transforaminal and epidural spread of the LA solution following an ESP block has been confirmed even in the absence of pneumoperitoneum. ${ }^{4}$ Therefore, a facilitated epidural spread of local anesthetic by increased intraabdominal pressure does not sound impossible in the case of an ESP block. We have previously referred to the study of Desmet $e t a l .{ }^{3}$ to mention the possible effect of pneumoperitoneum on extension of local anesthetic

\footnotetext{
B. Altiparmak, MD ( $)$

Department of Anesthesiology and Reanimation, Muğla Sitkı Koçman University, Muğla, Turkey

e-mail: basak_ugurlu@yahoo.com
}

M. Korkmaz Toker, MD · A. İ. Uysal, MD

Departmant of Anesthesiology and Reanimation, Muğla Sitkı Koçman University Training and Research Hospital, Muğla, Turkey solutions through interfascial planes. Nevertheless, different effects during different interfascial plane blocks is not surprising.

Elkoundi et al. ${ }^{1}$ also suggested the effect of a high volume of LA as a potential reason for epidural spread; we mentioned the same possibility in our previous correspondence. $^{2}$ Nevertheless, Adhikary et $a .^{5}$ performed an ESP block in a cadaveric model using only $20 \mathrm{~mL}$ of radiocontrast dye solution, and all block interventions resulted in transforaminal and epidural spread of LA solution.

In conclusion, we agree with the authors that a high volume of LA solution is more likely to have an effect on the epidural spread of LA solution during an ESP block; however, increased intraabdominal pressure from a pneumoperitoneum should not be so easily discounted on the basis of effects seen with the TAP block.

Conflicts of interest None.

Funding statement None.

Editorial responsibility This submission was handled by Dr. Hilary P. Grocott, Editor-in-Chief, Canadian Journal of Anesthesia.

\section{References}

1. Elkoundi A, Mustapha B, El Koraichi A. Potential mechanism for bilateral sensory effects after a unilateral erector spinae plane block. Can J Anesth 2020; 67: DOI: https://doi.org/10.1007/ s12630-020-01580-0.

2. Altiparmak B, Korkmaz Toker M, Uysal Aİ. Potential mechanism for bilateral sensory effects after unilateral erector spinae plane blockade in patients undergoing laparoscopic cholecystectomy. Can J Anesth 2019; 67: 161-2. 
3. Desmet $M$, Helsloot D, Vereecke E, Missant $C$, van de Velde $M$. Pneumoperitoneum does not influence spread of local anesthetics in midaxillary approach transversus abdominis plane block: a descriptive cadaver study. Reg Anesth Pain Med. 2015; 40: 34954.

4. Schwartzmann A, Peng P, Maciel MA, Forero M. Mechanism of the erector spinae plane block: insights from a magnetic resonance imaging study. Can J Anesth 2018; 65: 1165-6.
5. Adhikary SD, Bernard S, Lopez H, Chin KJ. Erector spinae plane block versus retrolaminar block: a magnetic resonance imaging and anatomical study. Reg Anesth Pain Med 2018; 43: 756-62.

Publisher's Note Springer Nature remains neutral with regard to jurisdictional claims in published maps and institutional affiliations. 